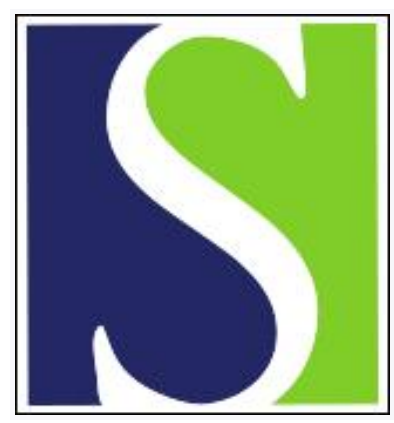

Scand J Work Environ Health Online-first -article

https://doi.org/10.5271/sjweh.3077

Published online: 05 Aug 2010

Physical activity and cardiovascular mortality - disentangling the roles of work, fitness, and leisure

by Krause $\mathrm{N}$

Affiliation: University of California at San Francisco, UC Berkeley Richmond, Richmond, CA 94804, USA. nkrause@berkeley.edu

Refers to the following texts of the Journal: $1994 ; 20(2): 73-86$ $1989 ; 15(3): 165-179 \quad 2000 ; 26(3): 227-236 \quad 2007 ; 33(6): 401-404$ 2007;33(6):405-424 2009;35(6):466-474 2010;36(5):366-372 $2010 ; 36(5): 357-365$

The following articles refer to this text: $2013 ; 39(5): 427-429$; 2015;41(2):124-139; 2016;42(4):291-298; 2016;42(5):423-434; 2017;43(3):210-216; 2022;48(2):86-98; 2023;49(3):231-244

Key terms: cardiovascular mortality; editorial; fitness; leisure; mortality; physical activity; work

This article in PubMed: www.ncbi.nlm.nih.gov/pubmed/20686737

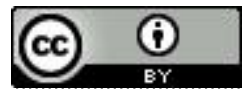




\section{Physical activity and cardiovascular mortality - disentangling the roles of work, fitness, and leisure}

Three recent papers in the Scandinavian Journal of Work, Environment \& Health by Holtermann et al $(1,2,3)$ report on a 30-year follow-up of over 5000 middle-aged, employed men enrolled in the Copenhagen Male Study; they provide new evidence for a detrimental role of occupational physical activity (OPA) and a protective role of cardiorespiratory fitness for all-cause and ischemic heart disease (IHD) mortality, among both healthy men (1) and men with pre-existing cardiovascular disease (CVD) (2). OPA also interacted with fitness (ie, high physical job demands were detrimental among workers with low and moderate levels of fitness but not among the most fit). Leisure-time physical activity (LTPA) had differential effects on mortality: protective effects for healthy men but not for men with pre-existing CVD. In addition, the authors note that there was no relationship between baseline OPA and fitness, which made them question a possible benefit of OPA in improving fitness. The relationship between LTPA and fitness was not reported. Moderate or high levels of LTPA did not further increase the elevated mortality risk experienced by men exposed to moderate or high levels of OPA if they were free of CVD, but no estimates were provided for men with CVD (3).

The study could be criticized for the crude 3-categorical exposure assessment, lack of repeat measures during a long follow-up time, or incomplete control for confounding; however, it is unlikely that the pattern of the findings could be explained by these limitations. In fact, a similar pattern of results was previously reported in this journal for the Finnish male population in the Kuopio IHD risk factor study of 11-year progression of sub-clinical carotid atherosclerosis using detailed continuous and repeat exposure measures. High energy expenditure at work accelerated progression, fitness slowed progression, and LTPA had no effect after controlling for each and virtually all other CVD risk factors [see appendix B in Krause et al (4)]. This sparked an editorial comment emphasizing the differences between OPA and LTPA (5). In the following, these recent findings are discussed in the context of the extant literature and with respect to future research needs.

How do these new findings compare to the previous epidemiological literature? Cardiorespiratory fitness, as measured by maximal oxygen consumption $\left(\mathrm{VO}_{2} \mathrm{Max}\right)$, has been shown consistently to be protective against CVD (6). A discrepancy between aerobic capacity and job demands has long been recognized by work physiologists as potentially harmful and individual measures of relative aerobic strain and oxygen uptake reserve capture this discrepancy. These individual relative measures of energy expenditure were not available in the Copenhagen data and have not yet been used in any other mortality study, but they were predictive of an accelerated 11-year progression of carotid atherosclerosis in the above-mentioned study of Finnish middle-aged men (4).

The Copenhagen results regarding OPA are also in agreement with three recent prospective studies independently reporting that greater physical activity during worktime is associated with increases in the risk of myocardial infarction and all-cause mortality (7-9). The World Health Organization (WHO)-sponsored 6-year prospective population-based MONICA study in Augsburg, Germany, found that occupationally physically active men experienced a $26 \%$ increased risk of myocardial infarction and a $91 \%$ increase in allcause mortality after controlling for several confounders (7). All-cause mortality was also elevated during 21 years of follow-up for Israeli government employees performing mainly physical labor (9). Results from the CORDIS study of industrial employees in Israel show a hazard ratio of 1.82 [95\% confidence interval 
$(95 \% \mathrm{Cl}) 1.18-2.81)$ for all cause mortality among workers with high physical workloads compared with workers having a low workload. Similar trends were noted for CVD and cancer mortality (8).

However, with regard to physical activity and CVD, the epidemiological literature is actually more inconsistent than is often recognized. Most epidemiological studies to date either failed to differentiate between physical activity during work and leisure time, or excluded OPA from their analyses altogether (10-13). While the beneficial effects of LTPA on the circulatory system appear well established (14, 15), the evidence about the health effects of OPA remains inconsistent (16). In high quality prospective population-based studies, higher levels of OPA were associated with a reduced risk of CVD in some studies (17-22), showed no association in others (18,21,23-28), or were associated with an increased CVD risk $(4,7-9,29)$. A few studies showed differential effects, with LTPA being protective and OPA having no effect (27), LTPA having no effect and OPA constituting a CVD risk (4), LTPA having a protective effect only among persons with low levels of OPA (22) or LTPA constituting a CVD risk (9). One case-control study reported an inverse relationship of LTPA with acute myocardial infarction but a u-shaped association with OPA (30).

These inconsistencies may be in part due to a misclassification of physical activity and uncontrolled confounding. Specifically, most studies used only crude categorical measures of OPA and did not assess changes in OPA during follow-up. Of the few studies that used a continuous measure of energy expenditure, only one adjusted for individual aerobic fitness that determines the actual cardiovascular load at any given job demand (4). The Copenhagen study is only the second study to control for fitness; unfortunately both fitness and physical demands were assessed in broad categories leading to avoidable misclassification and results that could be sensitive to the choice of cut-off points. Only two epidemiologic cohort studies adjusted for psychosocial job factors $(4,29)$, although job stress has been found to be an important risk factor for CVD in several studies (31-33) and could confound associations between OPA and CVD. For example, in their pioneering works, Morris et al (34) attributed the lower risk of coronary heart disease among London bus conductors versus drivers to the sedentary work of the drivers. Since then research has shown that the excess risk in CVD among urban bus drivers is not experienced by rural bus drivers, and, among urban bus drivers, is independent of both LTPA and OPA $(35,36)$. Instead the excess risk is now thought to be attributable to the high levels of job stress experienced by urban bus drivers (37-40), a factor that may have confounded the reported association with sedentary work $(8,16)$. Clearly, exposure misclassification and lack of control for psychosocial job factors are major limitations of most studies.

LTPA has numerous health benefits but its physiologic training effect on the heart is key to understanding the different effects of OPA and LTPA: LTPA can increase fitness and reduce heart rates during daily activities including work. The lower the heart rate, the longer the heart remains in diastole, and the better the perfusion of the myocardium because, in contrast to all other arteries, coronary arteries take in fresh oxygenated blood during diastole. But the diastole is also the more favorable phase of the cardiac cycle for all other arteries: hemodynamic flow and shear stress at the arterial wall are relatively constant and in a more optimal range during diastole compared to systole when oscillation of shear stress and arterial wall pressures may induce inflammatory changes in the arterial walls resulting in atherosclerosis $(41,42)$. The crucial point being: to achieve a training effect on the heart, relatively short ( $<1$ hour daily) but intensive bursts of exhausting conditioning physical activity are needed. Workers, however, who have to stand and walk, lift and carry, or otherwise work manually for multiple hours a day need to pace themselves and avoid such exertions in order to make it through the day. Therefore, OPA may not provide the desired training effect of a lower heart rate but instead elevate heart rates and shorten cumulative time in diastole during the workday. Indeed, work physiologists, while recognizing the potential training effects of LTPA, report that heavy dynamic and especially static work on the job can have more of an overloading than a training effect on the cardiovascular system (43). 
Recently published epidemiologic studies of middle-aged men from the Kuopio region are in agreement with this physiologic perspective. A significant association was found between static standing work postures and 4-year progression of atherosclerosis and between energy expenditure, relative aerobic strain, and relative oxygen uptake reserve at work and 11-year progression of carotid atherosclerosis after controlling for LTPA, fitness, socioeconomic status, psychosocial job factors, and virtually all known biological and behavioral risk factors $(4,29)$. In contrast to the Copenhagen study, men with pre-existing CVD were especially vulnerable to high levels of OPA regardless of OPA measure (this discrepancy may be the result of different definitions of pre-existing CVD). Of special concern is the observation, that the maximum level of relative aerobic strain recommended by work physiologists was exceeded by $31 \%$ of all middle-aged Finnish men and $>50 \%$ of all men with IHD, and that higher levels of aerobic strain predicted an accelerated progression of atherosclerosis (4). It is also noteworthy that caloric job demands did not materially decline over a full decade for those who remained employed in their jobs; instead they had to expend the same amount of energy each day at ever lower levels of fitness during follow-up $\left(\mathrm{VO}_{2} \mathrm{Max}\right.$ falls by about $1 \%$ per year after age 25) (4).

The high proportion of workers at elevated risk in Kuopio is probably not an exception. A representative population-based study from Sweden found that $27 \%$ of working men and $22 \%$ of working women were required to do work that exceeded their aerobic capacity (44). In Canada, about $60 \%$ of the workforce report working nearly exclusively in a standing position (45). In Denmark, about one quarter of the total workforce reports standing or walking $>75 \%$ of the workday (46). Clearly, even in so-called modern service economies, a large proportion of the working population is still exposed to heavy physical labor, and aging workers, especially those with existing IHD, are vulnerable to the detrimental effects of excessive caloric and static demands at work. Therefore, occupational health research needs to investigate both ends of the spectrum - too little beneficial as well as too much detrimental physical activity.

Why is more research focused on OPA and CVD needed? First, from an occupational health perspective, it is mandatory to protect workers from excessive physical job demands and address needs for optimal rehabilitation and ergonomic or work-schedule modifications to reduce aerobic strain and facilitate a safe return to work after the diagnosis of CVD. Second, from a social policy perspective, there is a need to assist aging workers in retaining their work ability so that they do not retire prematurely at a rate that already strains pension systems and has led to forecasts of severe labor shortages (47). Third, from a public health perspective, CVD is still the leading cause of death and accounts for $29 \%$ of all deaths worldwide, $37 \%$ of all deaths in developed regions, and $21 \%$ of disability-adjusted life years in developed regions. IHD is the most prevalent CVD (48). Fourth, occupational gradients in IHD incidence or mortality have been reported from many different populations and the widest gaps were consistently found between manual and non-manual occupations (49-51). Prospective studies have shown that differences in traditional biological and behavioral risk factors can explain only a small proportion of the observed inequalities (52). Specifically, it has been estimated that $<50 \%$ of the incidence of myocardial infarction can be explained by traditional risk factors (53) and only $25-30 \%$ of the observed occupational gradient (54). Psychosocial aspects of work have been suggested as alternative explanations, however, associations between job stress and CVD have been inconsistent and may be partly confounded by physical job demands (4). Fifth, trends of an increasing inequality in CVD also point to OPA as a potential key risk factor. In most developed regions, IHD incidence rates have declined since the 1980s but the lower socioeconomic groups did not participate equally in this overall decline, in fact, in some countries, lower occupational classes have been experiencing increasing rates of IHD and CVD risk factors (55). In Denmark, for example, overall IHD incidence decreased between 1981-1993. However, unskilled and skilled workers, who had already the highest rates in 1981, experienced a 12-year increase while rates of salaried employees were lower and decreased during the same time period (40). No studies have yet investigated if 
secular trends of increasing intensity of work and especially static work in industrialized countries during the same time period could have contributed to this widening gap in IHD incidence.

In terms of attributable risk, only one European study of CVD attempted to provide estimates for specific work exposures and attributed $1 \%$ of CVD to noise, $7 \%$ to shift-work, $2 \%$ to passive smoking, $3-13 \%$ to job strain, and $42 \%$ to sedentary work (56). Because the definition of sedentary work includes both "sitting and light standing work", it is not clear how much of the risk is actually due to standing work postures. Regardless of the methodological limitations of such estimates, sedentary work definitely ranks first on the list. This is in agreement with risk factor assessments in the general population, where the attributable risk of a "sedentary lifestyle" has also been ranked first, ahead of other traditional risk factors including smoking, hypertension, blood lipids, and obesity, in that order (57). Clearly, sedentary work needs to be considered a major determinant of CVD with a substantial potential for primary prevention at the workplace. Occupational health research in this area could contribute substantially to ongoing public health efforts in preventing CVD at the population level by active surveillance and prevention of work-related CVD risks due to both sedentary work and excessive relative aerobic strain.

However, the studies published in this journal indicate that more research is needed to differentiate between beneficial and detrimental levels of different types of OPA and how overexertion at work, job stress, and prolonged work time (58) may put workers at risk and prevent them from engaging in beneficial types of LTPA or simply get the recovery time they need. This research also needs to include surveillance of occupational CVD risks and utilize prospective designs and theoretically derived causation models to disentangle the relationships between fitness, OPA, and LTPA while simultaneously assessing biological, behavioral, and workplace psychosocial factors (55). Furthermore, new research should differentiate between specific vulnerable populations such as aging, female, and manual workers, or those with existing chronic conditions like CVD. These groups deserve their own guidelines about "good" and "bad" levels and types of both OPA and LTPA. An undifferentiated public health message of "more physical activity is better" is not helpful for workers whose physical job demands already exceed their aerobic capacity.

The most obvious research gap regarding physical activity and CVD concerns the unknown interrelationships between OPA, fitness, and LTPA. Only the two recent Danish and Finnish cohort studies simultaneously assessed the independent effects of fitness, OPA, and LTPA. The following suggestions may help address this gap and open the way to a broader clinical and public health approach to CVD prevention including an occupational health perspective.

First, it is cost-efficient to follow the example of the Danish researchers and utilize existing datasets from population-based cohort studies that gathered information on occupational factors but which have never been analyzed (59) to investigate independent and combined effects of OPA, LTPA, and fitness.

Second, improve exposure measures. Absolute measures of physical workload should be supplemented with relative measures of energy expenditure taking body weight and individual aerobic capacity into account. Whenever possible, categorization of continuous data should be avoided and the shape of dose-response curves explored, allowing for u-shaped and other curvilinear relationships. New studies should also explore the use of objective measures (eg, ambulatory heart rate monitors and accelerometers) but at the same time retain the best self-report measures until the validity of any new assessment method has been fully established. Whenever available, repeat exposure measures should be employed, especially in mortality studies with long follow-up times.

Third, focus on multivariate models with adjustment for traditional risk factors and also for job stress, job insecurity, and other potent psychosocial job factors that may confound the effects of OPA. One needs to be mindful that there is only theory - and no statistical method - to differentiate between confounding and mediating covariates. When in doubt (eg, does adjustment for income represent an over-adjustment or not?), it would be appropriate to present multivariate models with and without the questionable covariates. The opportunity to compare these different models enables the reader to evaluate the impact of 
respective pathway assumptions on effect sizes. It also facilitates comparisons with other studies that may differ with regard to the covariates for which they controlled. Explicit analyses of pathways using structural equation modeling and other techniques for the study of causal pathways should supplement the classic investigation of independent effects.

Fourth, determine if and how OPA, working time, commuting, and competing demands at home determine LTPA and fitness.

Fifth, explore interactions of OPA with fitness, age, gender, pre-existing CVD, and other chronic health conditions. It is important to determine risk profiles for different worker sub-populations in order to avoid undifferentiated one-size-fits-all approaches and instead develop specific evidence-based policies that meet the needs of aging workers, manual workers, CVD patients, immigrant workers, and other vulnerable groups.

Sixth, develop CVD risk scores that take traditional biological and behavioral risk factors and occupational and other environmental risk factors into account. This would assist clinicians and patients to make more informed diagnostic, therapeutic, and behavioral choices and would at the same time help to broaden public awareness of the importance of workplace determinants of CVD.

Finally, develop, disseminate, and evaluate practical guidelines for workplace surveillance of OPA and its risks. Such programs should probably include ambulatory heart rate monitoring to estimate relative aerobic strain for workers required to perform heavy physical labor, older workers, and workers with CVD and other chronic conditions associated with reduced fitness (4). Regulatory statutes dealing with work time and rest schedules need to assure that workers are protected from excessive aerobic strain even if individual monitoring is not available.

The evidence gained in this way could form the basis for the development of new primary, secondary, and tertiary prevention programs aiming at the prevention of CVD occurrence and progression, optimal rehabilitation of CVD patients, facilitation of safe return to work after CVD diagnoses, and increased wellbeing for all workers irrespective of their age, gender, fitness, health status, or socioeconomic position.

Niklas Krause, MD, PhD, MPH

University of California at San Francisco

UC Berkeley Richmond Field Station

1301 South 46th Street, Building 163

Richmond, CA 94804, USA

[E-mail: nkrause@berkeley.edu]

\section{References}

1. Holtermann A, Mortensen OS, Burr H, Søgaard K, Gyntelberg F, Suadicani P. Physical demands at work, physical fitness, and 30-year ischaemic heart disease and all-cause mortality in the Copenhagen Male Study. Scand J Work Environ Health. 2010;36(5):357-65.

2. Holtermann A, Mortensen OS, Burr H, Søgaard K, Gyntelberg F, Suadicani P. Fitness, work, and leisure-time physical activity and ischaemic heart disease and all-cause mortality among men with pre-existing cardiovascular disease. Scand J Work Environ Health. 2010;36(5):366-372.

3. Holtermann A, Mortensen OS, Burr H, Søgaard K, Gyntelberg F, Suadicani P. The interplay between physical activity at work and during leisure time - risk of ischemic heart disease and all-cause mortality in middle-aged Caucasian men. Scand J Work Environ Health. 2009;35(6):466-74.

4. Krause N, Brand RJ, Kaplan GA, Kauhanen J, Malla S, Tuomainen T, et al. Occupational physical activity, energy expenditure, and 11-year progression of carotid atherosclerosis. Scand J Work Environ Health. 2007;33(6):405-24.

5. Kukkonen-Harjula K. Physical activity and cardiovascular health-work and leisure differ [editorial]. Scand J Work Environ Health. 2007;33(6):401-4.

6. Kodama S, Saito K, Tanaka S, Maki M, Yachi Y, Asumi M, et al. Cardiorespiratory fitness as a quantitative predictor of all-cause mortality and cardiovascular events in healthy men and women: a meta-analysis. JAMA. 2009;301(19):2024-35.

7. Stender M, Hense HW, Doring A, Keil U. Physical activity at work and cardiovascular disease risk: results from the MONICA Augsburg study. Int J Epidemiol. 1993;22(4):644-50. 
8. Kristal-Boneh E, Harari G, Melamed S, Froom P. Association of physical activity at work with mortality in Israeli industrial employees: the CORDIS study. J Occup Environ Med. 2000;42(2):127-35.

9. Eaton CB, Medalie JH, Flocke SA, Zyzanski SJ, Yaari S, Goldbourt U. Self-reported physical activity predicts long-term coronary heart disease and all-cause mortalities: twenty-one-year follow-up of the Israeli Ischemic Heart Disease Study. Arch Fam Med. 1995;4(4):323-9.

10. US Department of Health and Human Services. Physical activity and health: a report of the Surgeon General. Atlanta, (GA): Centers for Disease Control and Prevention, National Center for Chronic Disease Prevention and Health Promotion; 1996. p 259.

11. Powell KE, Thompson PD, Caspersen CJ, Kendrick JS. Physical activity and the incidence of coronary heart disease. Annu Rev Public Health. 1987;8:253-87.

12. Berlin JA, Colditz GA. A meta-analysis of physical activity in the prevention of coronary heart disease. Am J Epidemiol. 1990;132(4):612-28.

13. Lee IM, Paffenbarger RS Jr, Hennekens CH. Physical activity, physical fitness and longevity. Aging (Milano). 1997;9(12):2-11.

14. Francesco S, Andrea C, Francesca C, Rosanna A, Gian Franco G. Physical activity during leisure time and primary prevention of coronary heart disease: an updated meta-analysis of cohort studies. Eur J Cardiovasc Prev Rehabil. 2008;15(3):247-57.

15. Nocon M, Hiemann T, Muller-Riemenschneider F, Thalau F, Roll S, Willich SN. Association of physical activity with all-cause and cardiovascular mortality: a systematic review and meta-analysis. Eur J Cardiovasc Prev Rehabil. 2008;15(3):239-46.

16. Kristal-Boneh E, Silber H. Notes on the health effects of leisure time versus work related physical activity. Isr J Occup Health. 1998;2:179-84.

17. Salonen JT, Puska P, Tuomilehto J. Physical activity and risk of myocardial infarction, cerebral stroke and death: a longitudinal study in Eastern Finland. Am J Epidemiol. 1982;115(4):526-37.

18. Menotti A, Seccareccia F. Physical activity at work and job responsibility as risk factors for fatal coronary heart disease and other causes of death. J Epidemiol Community Health. 1985;39(4):325-9.

19. Seccareccia F, Menotti A. Physical activity, physical fitness and mortality in a sample of middle aged men followed-up 25 years. J Sports Med Phys Fitness. 1992;32(2):206-13.

20. Salonen JT, Slater JS, Tuomilehto J, Rauramaa R. Leisure time and occupational physical activity: risk of death from ischemic heart disease. Am J Epidemiol. 1988;127(1):87-94.

21. Lapidus L, Bengtsson C. Socioeconomic factors and physical activity in relation to cardiovascular disease and death: a 12 year follow up of participants in a population study of women in Gothenburg, Sweden. Br Heart J. 1986;55(3):295-301.

22. Hu G, Jousilahti P, Borodulin K, Barengo NC, Lakka TA, Nissinen A, et al. Occupational, commuting and leisure-time physical activity in relation to coronary heart disease among middle-aged Finnish men and women. Atherosclerosis. 2007;194(2):490-7.

23. Kannel WB, Belanger A, D'Agostino R, Israel I. Physical activity and physical demand on the job and risk of cardiovascular disease and death: the Framingham Study. Am Heart J. 1986;112(4):820-5.

24. Sobolski J, Kornitzer M, De Backer G, Dramaix M, Abramowicz M, Degre S, Denolin H. Protection against ischemic heart disease in the Belgian Physical Fitness Study: physical fitness rather than physical activity? Am J Epidemiol. 1987;125(4):601-10.

25. Johansson S, Rosengren A, Tsipogianni A, Ulvenstam G, Wiklund I, Wilhelmsen L. Physical inactivity as a risk factor for primary and secondary coronary events in Goteborg, Sweden. Eur Heart J. 1988;9 suppl L:8-19.

26. Menotti A, Keys A, Blackburn H, Aravanis C, Dontas A, Fidanza F, et al. Twenty-year stroke mortality and prediction in twelve cohorts of the Seven Countries Study. Int J Epidemiol. 1990;19(2):309-15.

27. Haapanen N, Miilunpalo S, Vuori I, Oja P, Pasanen M. Characteristics of leisure time physical activity associated with decreased risk of premature all-cause and cardiovascular disease mortality in middle-aged men. Am J Epidemiol. 1996;143(9):870-80.

28. Harmsen P, Rosengren A, Tsipogianni A, Wilhelmsen L. Risk factors for stroke in middle-aged men in Goteborg, Sweden. Stroke. 1990;21(2):223-9.

29. Krause N, Lynch JW, Kaplan GA, Cohen RD, Salonen R, Salonen JT. Standing at work and progression of carotid atherosclerosis. Scand J Work Environ Health. 2000;26(3):227-36.

30. Lopes C, Santos AC, Azevedo A, Maciel MJ, Barros H. Physical activity and risk of myocardial infarction after the fourth decade of life. Rev Port Cardiol. 2005;24(10):1191-207.

31. Kristensen TS. Cardiovascular diseases and the work environment: a critical review of the epidemiologic literature on nonchemical factors [review]. Scand J Work Environ Health. 1989;15(3):165-79.

32. Schnall PL, Belkic K, Landsbergis P, Baker D, editors. The workplace and cardiovascular disease. Philadelphia (PA): Hanley \& Belfus; 2000. State of the Art Reviews in Occupational Medicine, volume 15, p 334.

33. Lynch JW, Krause N, Kaplan GA, Cohen R, Salonen R, Salonen JT. Workplace demands, economic reward, and the progression of carotid atherosclerosis. Circulation. 1997;96(1):302-7.

34. Morris JN, Kagan A, Pattison DC, Gardner MJ. Incidence and prediction of ischaemic heart-disease in London busmen. Lancet. 1966;2(7463):553-9.

35. Rosengren A, Anderson K, Wilhelmsen L. Risk of coronary heart disease in middle-aged male bus and tram drivers compared to men in other occupations: a prospective study. Int J Epidemiol. 1991;20(1):82-7.

36. Gustavsson P, Alfredsson L, Brunnberg H, Hammar N, Jakobsson R, Reuterwall C, Ostlin P. Myocardial infarction among male bus, taxi, and lorry drivers in middle Sweden. Occup Environ Med. 1996;53(4):235-40. 
37. Belkić K, Savić Č, Theorell T, Rakić L, Ercegovac D, Djordjević M. Mechanisms of cardiac risk among professional drivers [review]. Scand J Work Environ Health. 1994;20(2):73-86.

38. Evans GW. Working on the hot seat: Urban bus operators. Accid Anal Prev. 1994;26(2):181-93.

39. Hartvig P, Midttun O. Coronary heart disease risk factors in bus and truck drivers: a controlled cohort study. Int Arch Occup Environ Health. 1983;52(4):353-60.

40. Tüchsen F, Endahl LA. Increasing inequality in ischaemic heart disease morbidity among employed men in Denmark 1981-1993: the need for a new preventive policy. Int J Epidemiol. 1999;28(4):640-4.

41. Glagov S, Giddens D, Ku D. Hemodynamics and atherosclerosis: insights and perspectives gained from studies of human arteries. Arch Pathol Lab Med. 1988;112:1018-31.

42. Thubrikar MJ, Robiscsek F. Pressure-induced arterial wall stress and atherosclerosis. Ann Thorc Surg. 1995;59(6):1594-603.

43. Ilmarinen J. Work and cardiovascular health: viewpoint of occupational physiology. Ann Med. 1989;21(3):209-14.

44. Karlqvist L, Leijon O, Härenstam A. Physical demands in working life and individual physical capacity. Eur J Appl Physiol. 2003;89(6):536-47.

45. Arcand R, Labrèche F, Messing K, Stock S, Tissot F. Travail et sante [Work and health]. In: Daveluy C, Pica L, Audet N, Courtemanche R, Lapointe F, Côté L, et al, editors. Enquête sociale et de santé 1998 [Social and Health Survey 1998]. Quebec (Canada): Institut de la statistique du Quebec; 2000. p 525-70.

46. Borg V, Burr H, editors. Danske lønmodtageres arbeijdsmiljø og helbred 1990-98 [Danish wage-earners working environment and health 1990-95]. Copenhagen: Arbeidsmiljøinstitutet; 1997.

47. Ilmarinen J. Towards a longer worklife!: ageing and the quality of worklife in the European Union. Helsinki: Finnish Institute of Occupational Health; 2005.

48. World Health Organisation (WHO). Global Burden of Disease: 2004 update. Geneva: WHO; 2008. p 153.

49. Marmot MG, Smith GD, Stansfeld S, Patel C, North F, Head J, et al. Health inequalities among British civil servants: the Whitehall II study [see comments]. Lancet. 1991;337(8754):1387-93.

50. Kunst AE, Groenhof F, Mackenbach JP, EU Working Group on Socioeconomic Inequalities in Health. Mortality by occupational class among men 30-64 years in 11 European countries. Soc Sci Med. 1998;46:1459-76.

51. Chandola T. Social class differences in mortality using the new UK National Statistics Socio-Economic Classification. Soc Sci Med. 2000;50:641-49.

52. Helmert U. Sozialschichtspezifische Unterschiede bei somatischen und verhaltensbezogenen Risikofaktoren fuer die koronare Herzkrankheit [Social-strata-specific differences in somatic and behavioral risk factors of coronary heart disease]. In: Mielck A, Bloomfield K, editors. Sozialepidemiologie [Social epidemiology]. München (Germany): Juventa; 2001. p 175-83.

53. Siegrist J. Die soziale Dimension von Herz-Kreislauf-Krankheiten [The social dimension of cardiovascular diseases]. In: Kaiser G, Siegrist J, Rosenfeld E, Wetzel-Vandai K, editors. Die zukunft der Medizin. Neue Wege zur Gesundheit [The future of medicine. a new way for health]. Frankfurt/Main (Germany): Campus Verlag; 1996. p 94-102.

54. Marmot MG, Bosma H, Hemingway H, Brunner E, Stansfeld S. Contribution of job control and other risk factors to social variations in coronary heart disease incidence. Lancet. 1997;350(9073):235-9.

55. Landsbergis PA. Assessing the contribution of working conditions to socioeconomic disparities in health: a commentary. Am J Ind Med.2010;53(2):95-103.

56. Kristensen TS, Kornitzer M, Alfredsson L, Marmor M. Social factors, work, stress and cardiovascular disease prevention in the European Union. Brussels: The European Heart Network; 1998. p 35.

57. Haapanen-Niemi N, Vuori I, Pasanen M. Public health burden of coronary heart disease risk factors among middle-aged and elderly men. Prev Med. 1999;28(4):343-8.

58. Krause N, Brand R, Kauhanen J, Kaplan G, Syme S, Wong C, Salonen J. Work time and 11-year progression of carotid atherosclerosis in middle-aged Finnish men. Prev Chron Dis. 2009;6(1):A13.

59. MacDonald LA, Cohen A, Baron S, Burchfiel CM. Occupation as socioeconomic status or environmental exposure?: a survey of practice among population-based cardiovascular studies in the United States. Am J Epidemiol. 2009;169(12):1411-21. 
